\title{
Constant Darkness Induces IL-6-Dependent Depression-Like Behavior through the NF- $\kappa$ B Signaling Pathway
}

\author{
Francisco J. Monje, ${ }^{1}$ Maureen Cabatic, ${ }^{1}$ Isabella Divisch, ${ }^{1}$ Eun-Jung Kim,,${ }^{1,3}$ Kurt R. Herkner, ${ }^{3}$ Bernd R. Binder,${ }^{2 \dagger}$ \\ and Daniela D. Pollak ${ }^{1}$ \\ Departments of ${ }^{1}$ Neurophysiology and Neuropharmacology and ${ }^{2}$ Vascular Biology, Center for Physiology and Pharmacology, and ${ }^{3}$ Department of Pediatrics \\ and Adolescent Medicine, Medical University of Vienna, 1090 Vienna, Austria
}

Substantial experimental evidence indicates a major role for the circadian system in mood disorders. Additionally, proinflammatory cytokines have been proposed to be involved in the pathogenesis of depression. However, the molecular elements determining the functional interplay between these two systems in depression have not been described as yet. Here we investigate whether long-term light deprivation in the constant darkness (DD) paradigm affects depression-like behavior in mice and concomitantly modulates the levels of proinflammatory cytokines. We find that after 4 weeks of DD, mice display depression-like behavior, which is paralleled by reduced hippocampal cell proliferation. This chronobiologically induced depressive state is associated with elevated levels of plasma IL-6 (interleukin-6) and IL-6 and Il1-R1 (interleukin 1 receptor, type I) protein levels in the hippocampus and also alters hippocampal protein levels of the clock genes per2 and npas2. Using pharmacological blockers of the NF- $\kappa B$ pathway, we provide evidence that the effects of DD on depression-like behavior, on hippocampal cell proliferation, on altered expressional levels of brain and plasma IL-6, and on the modulation of clock gene expression are mediated through NF- $\kappa$ B signaling. Moreover, NF- $\kappa \mathrm{B}$ activity is enhanced in hippocampal tissue of DD mice. Mice with a deletion of IL-6, one of the target genes of NF- $\kappa \mathrm{B}$, are resistant to DD-induced depression-like behavior, which suggests a pivotal role for this cytokine in the constant darkness mouse model of depression. We here first describe some of the molecular elements bridging chronobiological and inflammatory processes in the constant darkness mouse model of depression.

\section{Introduction}

Mood disorders, including depression, comprise some of the most prevalent and debilitating forms of mental illnesses worldwide. These diseases are burdensome and life threatening for the affected individuals and have profound socioeconomic consequences. Depression has been tightly linked to disturbances of circadian rhythms, and alterations in emotional states have been found to affect circadian rhythms (Wirz-Justice, 2006). Seasonal affective disorders, a subtype of major depressive disorders related to seasonal variations in natural light levels, occur at higher prevalence in the more northern latitudes, in regions with extended periods of restricted sunlight (Rosen et al., 1990). In rats, long-term exposure to constant darkness (DD) has been shown to

\footnotetext{
Received March 26, 2011; accepted May 3, 2011

Author contributions:F.J.M., B.R.B., and D.D.P. designed research;F.J.M., M.C., I.D., E.-J.K., and D.D.P. performed research; F.J.M., K.R.H., and D.D.P. analyzed data; F.J.M. and D.D.P. wrote the paper.

${ }^{\dagger}$ Deceased, Aug. 28, 2010.

D.D.P. was supported by the Austrian Science Fund (FWF, P22424). The skilful help of Milena Savija with ELISA experiments is strongly appreciated. We thank Jonathan R. L. Monje for patient support during the preparation and revision of the manuscript.

This article is dedicated to the memory of Prof. Bernd R. Binder, the late head of the Center for Physiology and Pharmacology at the Medical University of Vienna, Austria.

The authors declare no competing financial interests.

This article is freely available online through the J Neurosci Open Choice option.

Correspondence should be addressed to Daniela D. Pollak, Department of Neurophysiology and Neuropharma-

cology, Center for Physiology and Pharmacology, Medical University of Vienna, Schwarzspanierstrasse 17, A-1090

Vienna, Austria. E-mail: daniela.pollak@meduniwien.ac.at.

DOI:10.1523/JNEUROSCI.1537-11.2011

Copyright $\odot 2011$ the authors $\quad 0270-6474 / 11 / 319075-09 \$ 15.00 / 0$
}

result in the development of a desipramine-sensitive depression-like behavioral phenotype (Gonzalez and Aston-Jones, 2008). In humans, depressed patients often present with sleep abnormalities ranging from insomnia and early-morning awakening to hypersomnia and reduced daytime alertness, together with disruption in the levels and phases of various circadian factors, such as core temperature or melatonin release (Souêtre et al., 1989; Fava, 2004; Baldwin and Papakostas, 2006; Lam, 2006; Srinivasan et al., 2006).

Disturbed day-night cycles and altered sleep patterns are also known to affect the rhythmic intradiem oscillations of elements of the immune system, such as IL-6 (Vgontzas et al., 2002, 2003). Interestingly, elevated inflammatory parameters, including IL-6, are also frequently observed in depressed patients. In accordance with these results, it has been reported that in rodents, application of immune-stimulating compounds and of specific cytokines themselves leads to the development of depression-like behavioral states that can be ameliorated by long-term antidepressant treatment (Anisman et al., 2005). Even though the involvement of the circadian system and inflammatory processes is supported by a wealth of data (Boivin, 2000; Anisman et al., 2005; Wirz-Justice, 2006; Dantzer et al., 2008), a physiological link between these two systems in the neurobiological disturbances leading to or presenting the depressed condition, and the molecular players involved, has not yet been determined, partially due to the lack of adequate animal models.

We therefore decided to use a particular case of circadian disruption, light deprivation in the DD paradigm, and to examine the potential involvement of inflammatory signaling in the associated depressive state by testing the following: first, whether 
DD serves as a chronobiological model for depression in mice; second, whether DD modulates circulating plasma cytokine profiles and cytokine and cytokine receptor protein levels in the hippocampus, a target brain region in depression, and whether the Erk1/2 cascade is involved; third, whether DD-induced depression-like behavior, effect on hippocampal cell proliferation, and inflammatory responses are dependent on the NF- $\kappa$ B signal transduction pathway, known to play a pivotal role in controlling cellular expression of proinflammatory genes (Irwin et al., 2008); fourth, whether in the DD model of depression, the behavioral phenotype and its associated inflammatory profile are paralleled by alterations in hippocampal protein levels of clock genes; and fifth, whether DD alters NF- $\kappa$ B signaling and whether IL-6 blockade reverses its behavioral effects.

\section{Materials and Methods}

\section{Animals and housing}

Adult C57BL/6N male mice (Charles River) and IL-6 knock-out (B6.129S2-Il ${ }^{\mathrm{tm} 1 \mathrm{Kopf}} / \mathrm{J}$ ) and wild-type control mice (Jackson Laboratories), 10-12 weeks old, were housed in pairs of two in standard transparent laboratory cages in a temperature-controlled colony room $\left(22 \pm 1^{\circ} \mathrm{C}\right)$ and were provided with food and water ad libitum unless stated otherwise. Mice were either maintained on a $12 \mathrm{~h}$ light/dark cycle (with lights on at 6:00 A.M., 200-220 lux inside the cages) (LD) or in $24 \mathrm{~h}$ of constant darkness (DD). Cages were cleaned once a week in regular white light (LD group) or in dim red light (1-2 lux, DD group). Following a 2 week habituation period under regular LD conditions, one group of mice was exposed to 4 weeks of DD, while control mice remained under LD conditions. At this time point, all animals were weighed once a week. All animal experiments are in line with the U.K. Animals (Scientific Procedures) Act, 1996, and associated guidelines (86/609/EEC) and were approved by the local animal committee.

\section{Wheel running activity}

To record daily running wheel behavior, animals were placed into individual cages containing plastic running wheels (diameter $15.5 \mathrm{~cm}$, Med Associates). Wheel running activity was continuously monitored through wireless transmitters and recorded using the Wireless Running Wheel Manager Data Acquisition Software (Med Associates). Data were exported from the wheel manager database for further analysis. To analyze the circadian rhythmicity in LD and DD mice, wheel running activity was determined in $60 \mathrm{~min}$ bins during a $72 \mathrm{~h}$ block starting 3 weeks after the onset of the $\mathrm{DD}$ and $\mathrm{LD}$ condition, respectively. The parameters evaluated included the period (duration of the rhythm) and the total wheel running activity (revolutions per $24 \mathrm{~h}$ ). The lights-on phase [light onset $=$ zeitgeber time (ZT) 0 to light offset $=\mathrm{ZT} 12]$ was defined as the rest period, whereas the active period was defined as the dark phase (light offset $=$ ZT 12 to light onset $=$ ZT 24) in LD mice. For the DD group, the onset of the active period was determined by the beginning of at least two continuous hourly waking epochs with amounts of wheel running activity equal to or larger than the total mean hourly amount recorded. Correspondingly, the onset of the rest period was determined by the beginning of at least two continuous hourly epochs with wheel running activity values lower than the total hourly mean recorded (González and Aston-Jones, 2006). Free-running activity periods were determined by a Lomb-Scargle periodogram procedure using the El Temps computer program (A. Díez-Noguera, University of Barcelona, Barcelona, Spain).

\section{Pharmacological inhibition of NF- $\kappa B$}

Pyrrolidine dithiocarbamate (PDTC, $50 \mathrm{mg} / \mathrm{kg}$ ) and acetylsalicylic acid (ASA, $45 \mathrm{mg} / \mathrm{kg}$ ) were purchased from Sigma-Aldrich and dissolved in $0.9 \%$ physiological saline and administrated using dosage regimens previously described (Brunello et al., 2006; Zhang et al., 2009) in a final injection volume of $5 \mathrm{ml} / \mathrm{kg}$. BAY 11-7082 (BAY) (Merck) was dissolved in $0.5 \%(\mathrm{v} / \mathrm{v})$ DMSO in $0.9 \%$ saline and used at a concentration of 5 $\mathrm{mg} / \mathrm{kg}$ as described previously (Rivas et al., 2008). Control mice received $5 \mathrm{ml} / \mathrm{kg}$ injections of saline $(0.9 \% \mathrm{NaCl})$ or $0.5 \%(\mathrm{v} / \mathrm{v}) \mathrm{DMSO}$ in $0.9 \%$
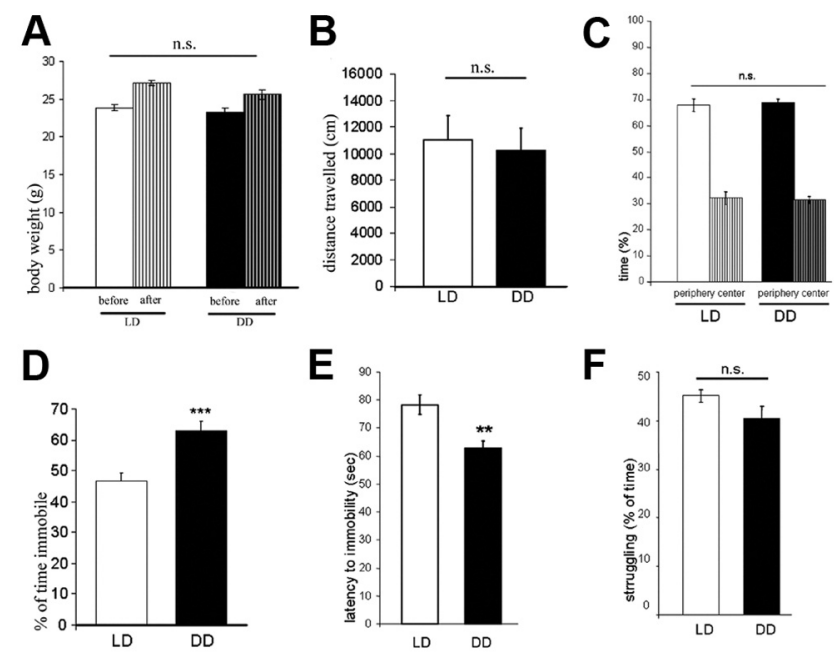

E

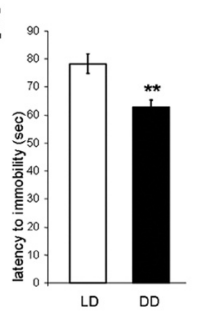

$\mathbf{F}$

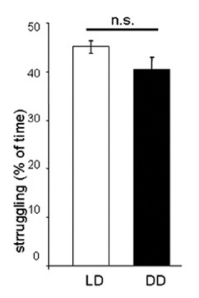

G
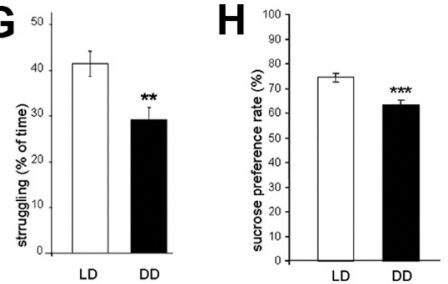

Figure 1. $A$, Body weight before the beginning and at the end of the experimental period. $\boldsymbol{B}$, Locomotor activity in the open field measured as total distance traveled (in centimeters). $\boldsymbol{C}$, Time spent in the center and the periphery of the open field. $\boldsymbol{D}$, Immobility (percentage of total time) in the forced-swim test. $\boldsymbol{E}$, Latency to immobility (in seconds) in the forced-swim test. $\boldsymbol{F}$, Percentage of time spent struggling during the first 2 min of the forced-swim test. G, Percentage of time spent struggling during the last $4 \mathrm{~min}$ of the forced-swim test. $\boldsymbol{H}$, Sucrose preference rate (percentage). All data are displayed as mean \pm SEM. $.{ }^{* *} p<0.01$, ${ }^{* * *} p<0.001$; n.s. (not significant), $p>0.05$.

saline, respectively. All drugs and were injected daily via an intraperitoneal route for the entire experimental period.

\section{Brain and blood sampling}

Brain and blood samples were collected between 10:00 and 11:00 A.M. (LD group) and 4:00 and 5:00 P.M. (DD group), corresponding to times of rest for each group as previously described (González and AstonJones, 2006) and confirmed by wheel running analysis. Mice were deeply anesthetized with ketamine $(100 \mathrm{mg} / \mathrm{kg}) /$ xylazine $(10 \mathrm{mg} / \mathrm{kg})$ and blood was collected via cardiac puncture into $1.5 \mathrm{ml}$ Eppendorf tubes (containing $7.5 \mathrm{U}$ heparin). Upon centrifugation $(12,000 \times g)$ at $4^{\circ} \mathrm{C}$ for $5 \mathrm{~min}$, plasma was collected and stored in aliquots at $-80^{\circ} \mathrm{C}$ until used for further analysis. The hippocampus was rapidly dissected and snap frozen in liquid nitrogen, and the tissue was stored at $-80^{\circ} \mathrm{C}$ until used.

\section{Behavioral testing}

Animals were handled daily for $3 \mathrm{~d}$ before start of behavioral experiments at the end of the experimental period. All behavioral testing was performed between 10:00 A.M. and 12:00 P.M. (LD group) and 3:00 and 5:00 P.M. (DD group), corresponding to times of rest for each group as previously described (González and Aston-Jones, 2006). Illumination was set at 80-90 lux (at the level of the animal) for the LD group and was provided by a red light lamp at 1-2 lux for the DD group.

Open field. The open field $(\mathrm{OF})$ was a rectangular Plexiglas arena $(40 \times$ $40 \times 60 \mathrm{~cm}$ ). Locomotor activity was recorded during $30 \mathrm{~min}$ using a CCD camera (Panasonic) and analyzed using the Limelight video tracking system (Actimetrics). Total distance traveled (in centimeters) as parameter for locomotor activity was automatically generated by the software. The equipment was cleaned using $70 \%$ ethanol between animals.

Forced swim test. Mice were placed into glass beakers $19 \mathrm{~cm}$ in diameter and $23 \mathrm{~cm}$ deep filled with $23-25^{\circ} \mathrm{C}$ water for $6 \mathrm{~min}$ and behaviors were monitored from above by video camera with night vision (Sony DCR- 
A
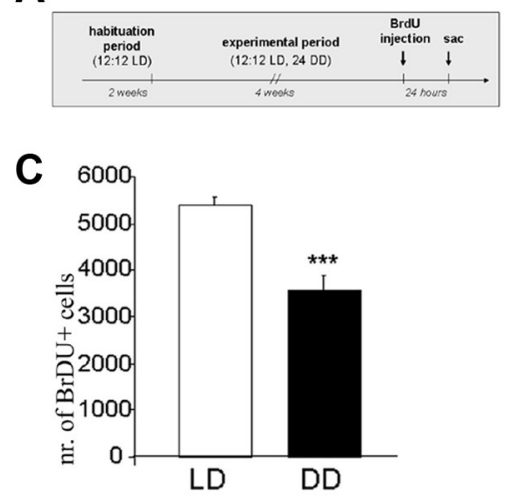

D

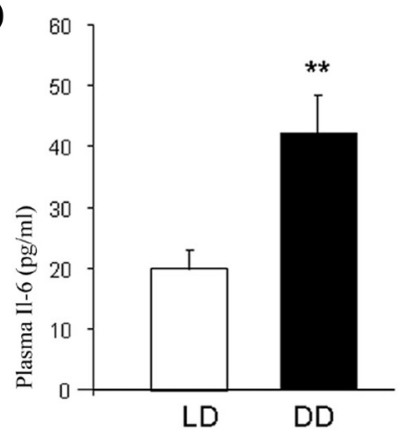

B

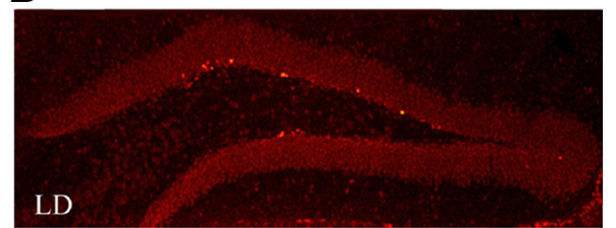

DD

$\mathbf{E}$

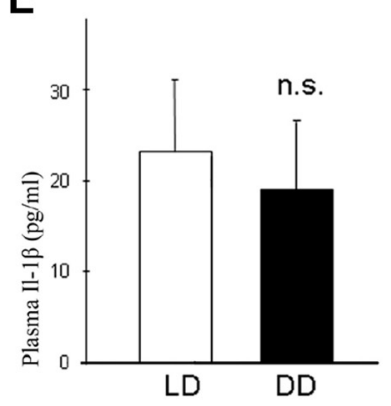

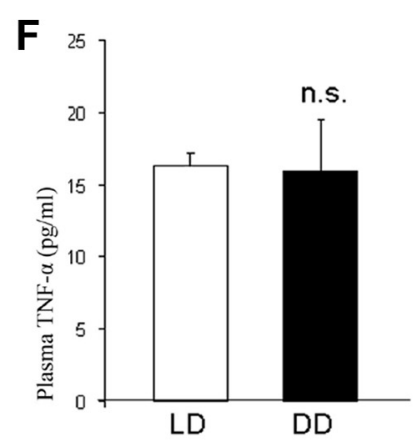

Figure 2. A, Design for assessment of hippocampal cell proliferation using BrdU labeling. $\boldsymbol{B}$, Representative image of immunohistochemical analysis of the hippocampal dentate gyrus depicting BrdU + cells (light red) in the subgranular zone in LD and DD mice. $C$, Quantitative evaluation of BrdU + cells in the hippocampal subgranular zone in LD and DD mice. $\boldsymbol{D}-\boldsymbol{F}$, Plasma levels of IL-6 (D), IL-1 $\beta(\boldsymbol{E})$, and TNF- $\alpha(\boldsymbol{F})$ (ELISA). All data are displayed as mean \pm SEM. ${ }^{* *} p<0.01,{ }^{* * *} p<0.001 ;$ n.s. (not significant), $p>0.05$.

PC110) for subsequent analysis. Behavioral patterns were scored by an experienced experimenter blind to the experimental conditions. A timesampling technique was used whereby the predominant behavior in each $5 \mathrm{~s}$ period was recorded (Cryan et al., 2002). The latency to the first bout of immobility was recorded starting immediately after placing the mice into the water. The minimal duration of a bout of immobility was set at $1 \mathrm{~s}$. A mouse was judged immobile when it ceased all active behaviors (i.e., struggling, swimming, and jumping) and remained passively floating or making minimal movements necessary to maintain the nostrils above water (Castagné et al., 2009). Struggling, defined as vigorous swimming movements involving all four limbs of the mouse with the front paws breaking the surface of the water (Steiner et al., 2008), was evaluated throughout the $6 \mathrm{~min}$ observation period, to rule out that intense activity during the first minutes may bias the results from the remaining time due to exhaustion. Immobility was scored only during the last $4 \mathrm{~min}$ according to the original description of the procedure (Porsolt et al., 1977). After the test, mice were dried and placed in their home cage.

Tail suspension test. The tail suspension test (TST) followed the protocol described previously (Ibarguen-Vargas et al., 2009). Briefly, mice were suspended by an adhesive tape placed $20 \mathrm{~mm}$ from the extremity of their tails on a horizontal bar $60 \mathrm{~cm}$ above the floor. Each mouse was given one trial of 5 min and the experiments were videotaped using a camera with night vision (Sony DCRPC110). Videotapes were scored by for immobility time by a trained experimenter blind to the experimental condition. Mice were considered immobile when they hung completely motionless.

Sucrose preference test. The sucrose preference test (SPT) was essentially performed as previously described (Pollak et al., 2008). Mice were given a $48 \mathrm{~h}$ exposure to two bottles, one containing $2 \%$ sucrose solution, the other autoclaved water, $72 \mathrm{~h}$ before the start of the experimental period (DD and LD). The bottles were counterbalanced across the left and right side of the feeding compartment after $24 \mathrm{~h}$. The volume of total fluid consumption and sucrose preference were evaluated after 24 and $48 \mathrm{~h}$ as prestress baseline (data not shown). On the last day of the experimental period, animals were deprived of food and water and tested for sucrose preference $23 \mathrm{~h}$ later. Testing was performed in the home cage in the form of a two bottle choice paradigm ( $2 \%$ sucrose vs water) during a $2 \mathrm{~h}$ free selection period. Sucrose preference rate was calculated according to the following formula: percentage preference $=($ sucrose intake $/$ total intake $) \times 100$.

Analysis of hippocampal cell proliferation For assessment of hippocampal cell proliferation, (+)-5' -bromo-2'-deoxyuridine (BrdU; $97 \%$, Sigma) (50 mg/kg, i.p.) was administered four times with $2 \mathrm{~h}$ intervals after 4 weeks of DD or LD. Mice were killed $24 \mathrm{~h}$ after the last BrdU injection ( $n=5$ per group). BrdU immunohistochemistry, imaging, and quantification of BrdU immunofluorescence were performed as previously described (Pollak et al., 2008).

\section{ELISA}

Frozen aliquots of plasma samples were thawed immediately before being used for ELISA experiments. ELISA analysis for plasma cytokine levels was performed using commercially available test kits (Ebioscience) following the manufacturer's instructions. All samples were analyzed in duplicates $(n=8-12$ per group). Photometric measurements were performed on an ELISA plate reader (Stat Fax-2100, Awareness Technologies). Calculation of results was obtained according to standard curves as provided in the test kits, analyzed together with the sample runs.

\section{Western blotting}

Hippocampal tissue was ground under liquid nitrogen and homogenized in a protein lysis buffer containing of $10 \mathrm{~mm}$ Tris- $\mathrm{HCl}, \mathrm{pH} 7.5,150 \mathrm{~mm}$ $\mathrm{NaCl}, 0.05 \%$ SDS, $0.5 \%$ Triton X100, 1 mM PMSF, and protease inhibitor cocktail (1×, Roche Diagnostics). Western blotting was performed essentially as previously described (Pollak et al., 2005). Membranes were blocked by incubating with $5 \%$ nonfat dry milk in $100 \mathrm{~mm}$ Tris, $\mathrm{pH} 7.5$, $150 \mathrm{~mm} \mathrm{NaCl}$, and $0.1 \%$ Tween 20 (TTBS). Membranes were then incubated with primary antibodies (IL-1 $\beta$ : Cell Signaling Technology; IL-6: Acris Antibodies; TNF- $\alpha$ : Cell Signaling Technology; IL-R1: Cell Signaling Technology; ERK1/2: Cell Signaling Technology; pERK1/2: Cell Signaling Technology; per1: Abcam; per2: Millipore; per3: Millipore; npas2: Abcam; $\beta$-tubulin: Acris Antibodies) overnight at $4{ }^{\circ} \mathrm{C}$, rinsed three times with TTBS, and incubated for $1 \mathrm{~h}$ at room temperature with horseradish peroxidase-conjugated secondary antibody (horse anti-mouse IgG, goat 
anti-rabbit IgG: Cell Signaling Technology). Immunoreactivity was visualized by enhanced chemiluminescence (ECL, GE Healthcare). Quantification was performed by chemiluminescent imaging with a FluorChem HD2 (Alpha Innotech) using the respective software. Values obtained from densitometry of target proteins were normalized to those of the housekeeping protein $\beta$-tubulin for the same samples. Protein levels of all samples ( $n=6-8$ per group) were calculated as ratios (fold changes) with respect to LD controls (saline).

\section{$N F-\kappa B$ activity assay}

Nuclear protein extracts were prepared from freshly dissected hippocampal tissue using a commercially available nuclear extraction kit (Active Motif) and following the manufacturer's instructions. Protein concentration was determined using a BCA assay (Pierce). Ten micrograms of nuclear protein extract were used for determining NF- $\kappa$ B transcription factor activity using the TransAM NF- $\kappa \mathrm{B}$ transcription factor assay kit (Active Motif) using antibodies against NF- $\kappa \mathrm{B}$ p65 and p50 according to the manufacturer's guidelines. Briefly, an ELISA plate coated with oligonucleotides containing an NF- $\kappa \mathrm{B}$ consensus regulatory element sequence was used for incubation of nuclear protein extracts. After incubation with an antibody specific for the p65 and p50 subunits of NF- $\kappa \mathrm{B}$, binding of the primary antibody was visualized using a horseradish peroxidase (HRP)-conjugated secondary antibody and the following chromogenic reaction. DNA binding specificity was assessed using mutated or wild-type oligonucleotides. Samples ( $n=6$ per group) were analyzed in duplicate and NF- $\kappa \mathrm{B}$ transcription factor activity was determined by absorbance reading at $450 \mathrm{~nm}$ using a spectrophotometer.

\section{Statistical analysis}

For statistical analyses of differences between two groups the unpaired two-tailed Student's $t$ tests were used. For experiments involving drug administration, two-way ANOVAs [2 (LD or DD) $\times 2$ (saline, PDTC, ASA)] followed by Scheffés post hoc tests for pairwise comparisons of significant ANOVA results. An $\alpha$ level of 0.05 was adopted in all instances. All analyses were performed using BioStat 2009 professional software (AnalystSoft).

\section{Results}

Constant darkness induces a depression-like behavioral phenotype in mice and leads to reduced hippocampal progenitor cell proliferation

Evaluation of the onset of active and rest periods in DD mice confirmed that the circadian cycle of these animals were freerunning, since a shift in wheel running activity of $\sim 13$ min per day was observed (period $=24.22 \pm 0.09 \mathrm{~h}, n=10$ ). Therefore, after 4 weeks of constant darkness, the beginning of the active period was shifted $\sim 7 \mathrm{~h}$ in DD mice with respect to LD controls. No significant differences in total wheel running activity (in revolutions per $24 \mathrm{~h})$ between DD $(27,243 \pm 2995)$ and LD mice $(28,584 \pm 2309)$ were observed ( $p>0.05)$. No significant differences in body weight gain between DD and LD groups of mice during the experimental period were observed $(p>0.05)$ (Fig. $1 A)$. After completion of the experimental period, mice of the $\mathrm{DD}(n=13)$ and LD $(n=12)$ groups were subjected to the OF test to confirm that DD did not affect locomotor activity. No significant differences between groups in total distance traveled (in centimeters) and time spent in center and periphery of the $\mathrm{OF}$ were detected ( $p>0.05$ ) (Fig. $1 B, C$ ). Twenty-four hours later, animals were tested in the forced swim test (FST) to evaluate depression-like behavior. DD mice spent a significantly higher percentage of time immobile than LD mice $(p<0.001)$ (Fig. $1 D$ ) and had a significantly lower latency to immobility $(p<0.01)$ (Fig. $1 E$ ). Analysis of struggling behavior revealed no significant differences between LD and DD mice in the first $2 \min (p>0.05)$ (Fig. $1 F$ ), while in the last $4 \mathrm{~min}$ of the FST, DD mice displayed significantly less struggling behavior $(p<0.001)$ (Fig. $1 G)$. An anhedonia-related phenotype of DD mice was revealed by signif-
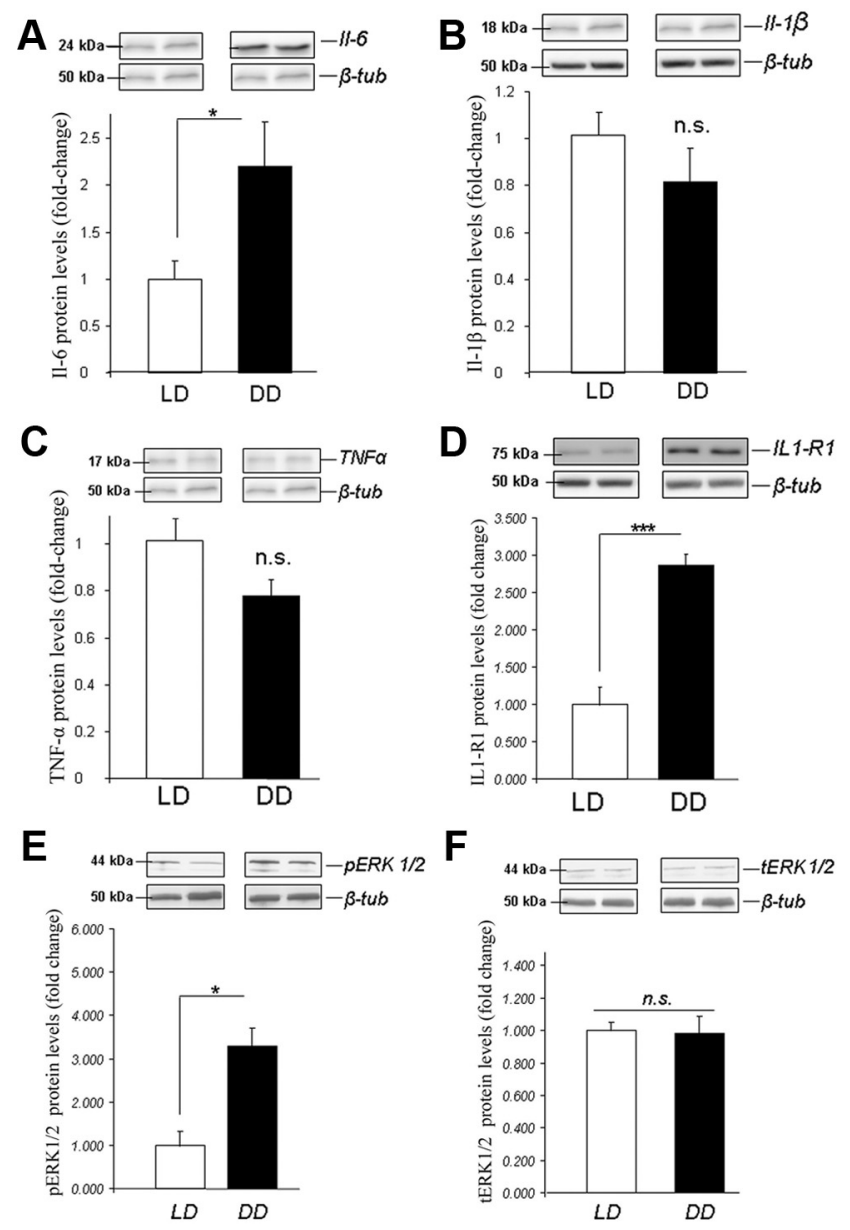

Figure 3. Hippocampal protein levels of IL-6 (A), IL-1 $\beta(\boldsymbol{B})$, TNF- $\alpha(\boldsymbol{C}), \| 1-R 1(\boldsymbol{D})$, pErk1/2 (phosphorylated Erk1/2) $(\boldsymbol{E})$, and tErk1/2 (total Erk1/2) $(\boldsymbol{F})$. Protein levels are ratios of optical densities. Values from the DD group are normalized to those of the LD controls. All data are displayed as mean \pm SEM. ${ }^{*} p<0.05,{ }^{* * *} p<0.001$; n.s. (not significant), $p>0.05$.

icantly reduced preference for sucrose in the SPT in parallel set of animals $(p<0.001)$ (Fig. $1 H$ ). Parallel groups of mice received injections of the thymidine analog BrdU at the end of the experimental period (Fig. 2A). Twenty-four hours after the last injection, the number of dentate gyrus newborn $\left(\mathrm{BrdU}^{+}\right.$cells) was significantly lower in DD compared to LD mice $(p<0.001)$ (Fig. $2 B, C)$.

\section{Constant darkness modulates plasma cytokine profiles and} hippocampal cytokine and cytokine receptor protein levels and leads to Erk1/2 activation

ELISA measurements of proinflammatory cytokines IL- $1 \beta$, IL-6, and TNF $\alpha$ in the plasma of DD and LD mice showed significantly higher levels of IL-6 in DD mice ( $p<0.01)$, while no differences in IL- $1 \beta$ and TNF $\alpha$ were observed ( $p>0.05$ ) (Fig. $2 D-F)$. The levels of IL- 6 in hippocampal tissue were also elevated in DD mice as revealed by densitometric analysis of Western blots $(p<0.05)$, while levels of IL- $1 \beta$ and TNF $\alpha$ were comparable among groups $(p>0.05)$ (Fig. 3A-C). Additionally, levels of Il1-R1 (interleukin 1 receptor, type I) were more than twofold higher in hippocampal tissue of DD than of LD mice $(p<0.001)$ (Fig. 3D). When examining levels of phosphorylated and total Erk1/2 (pErk and tErk), we found a more than twofold increase in pErk1/2 in hippocampal tissue of DD mice, whereas no effect on tErk1/2 was observed (Fig. $3 E, F$ ). 
A

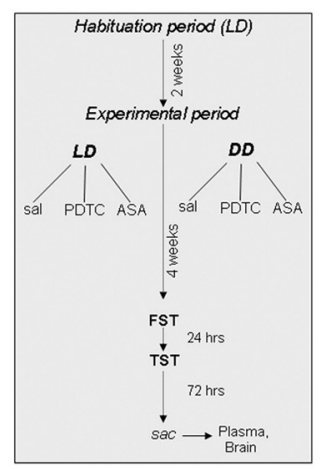

B

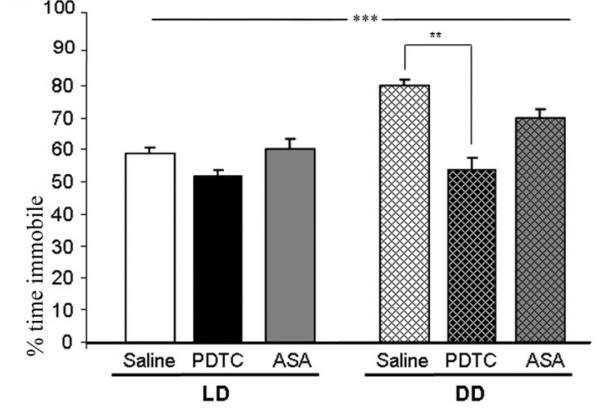

C

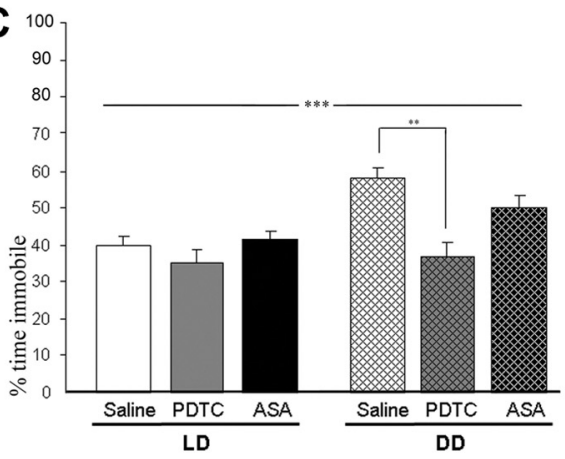

E

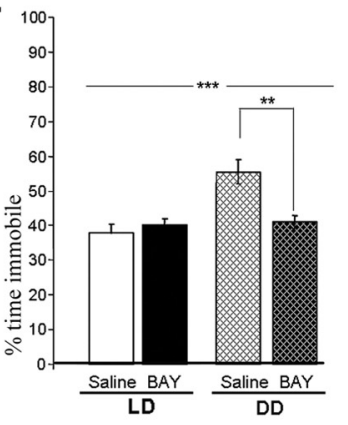

D

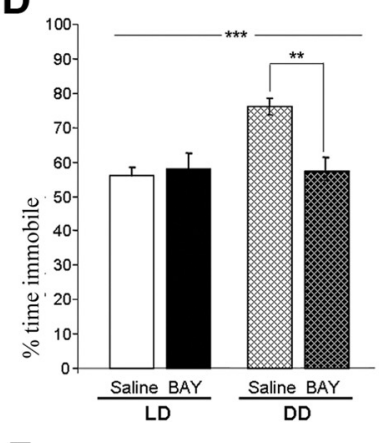

$\mathbf{F}$

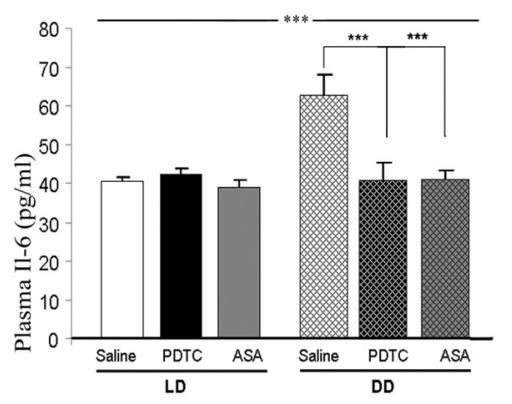

Figure 4. $\quad \boldsymbol{A}$, Design of pharmacological treatments, assignment to experimental groups and behavioral testing and tissue sampling procedure. $\boldsymbol{B}, \boldsymbol{C}$, Immobility (percentage of total time) in the forced-swim test $(\boldsymbol{B})$ and in the tail-suspension test $(\boldsymbol{C})$ in saline controls and PDTC- $(50 \mathrm{mg} / \mathrm{kg})$ and ASA- (45 mg/kg) treated DD and LD mice. $\boldsymbol{D}, \boldsymbol{E}$, Immobility (percentage of total time) in the forced-swim test $(\boldsymbol{D})$ and in the tail-suspension test $(\boldsymbol{E})$ in saline controls and BAY $(5 \mathrm{mg} / \mathrm{kg})$-treated DD and LD mice. $\boldsymbol{F}$, Plasma levels of IL-6 in saline-, PDTC-, and ASA-treated DD and LD mice. All data are displayed as mean \pm SEM. ${ }^{* *} p<0.01,{ }^{* * *} p<0.001$.

Constant darkness-induced depression-like phenotype, alterations of circulating and hippocampal IL-6 levels, and reduction in hippocampal cell proliferation are dependent on the NF- $\kappa \mathrm{B}$ signaling pathway

LD and DD mice ( $n=40-45$ per group) were randomly assigned to one of the three drug treatment regimens (saline, PDTC, or ASA; $n=12-15$ per group) (Fig. $4 A$ ) and depression-like behavior was evaluated at the end of the experimental period using the FST and the TST. In both the FST and the TST, there was a significant main effect of the light condition (FST: $F_{(1,56)}=25.50$, $p<0.0001$; TST: $\left.F_{(1,56)}=11.29, p<0.01\right)$ and drug treatment $\left(\right.$ FST: $F_{(2,56)}=17.23, p<0.0001$; TST: $\left.F_{(2,56)}=6.55, p<0.01\right)$ and a significant interaction (light $\times$ drug) (FST: $F_{(2,56)}=3.18$, $p<0.05$; TST: $\left.F_{(2,56)}=3.31, p<0.05\right)$. For both behavioral paradigms, post hoc comparisons revealed a significant difference between DD saline- and PDTC-treated $(p<0.01)$ mice (Fig. $4 B, C)$. A third NF- $\kappa$ B inhibitor, BAY, was then used to confirm that the behavioral effect of drug treatment ( $n=8-10$ per group) indeed indicated a causal involvement of the NF- $\kappa \mathrm{B}$ signaling pathway in DD-induced depression-like behavior. Apart from the significant main effect of the light condition, there was a highly significant main effect of drug treatment $\left(\mathrm{FST}: F_{(1,32)}=20.00, p<\right.$ 0.0001; TST: $F_{(1,32)}=10.41, p<0.01$ and a significant interaction (light $\times$ drug) $\left(\right.$ FST: $F_{(2,32)}=7.04, p<0.05$; TST: $F_{(2,32)}=$ $5.19, p<0.05)$. In both tests, a significant difference between DD saline- and BAYtreated mice was determined by post hoc comparisons ( $p<0.01$ for both tests) (Fig. $4 D, E$ ).

For plasma IL-6 levels, two-way ANOVA analysis (light $X$ drug) revealed a significant main effect of the light condition $(\mathrm{LD}, \mathrm{DD})\left(F_{(1,50)}=23.89, p<0.0001\right)$, a significant main effect of drug (PDTC, ASA, saline) $\left(F_{(2,50)}=10.96, p<0.0001\right)$, and a significant interaction (light $\times$ drug) $\left(F_{(2,50)}=5.75, p<0.01\right)$ Post hoc comparisons demonstrated statistically significant differences between DD saline controls and PDTC- and ASA-treated mice $(p<0.001)$ (Fig. $4 F$ ). For hippocampal IL-6, a significant main effect of light condition $\left(F_{(1,23)}=\right.$ $27.16, p<0.0001)$, significant main effect of $\operatorname{drug}\left(F_{(2,23)}=6.26, p<0.01\right)$, and a significant interaction (light $\times$ drug $)\left(F_{(2,23)}=\right.$ $15.82, p<0.0 .0001)$ was determined. Post hoc comparisons showed statistically significant differences between DD saline controls and PDTC- and ASA-treated mice $(p<0.01)$ (Fig. 5A).

To determine whether NF- $\kappa$ B is causally involved in the dampening effects of DD on hippocampal cell proliferation, another set of mice was treated with PDTC or saline and used for BrdU administration and determination of dentate gyrus cell proliferation at the end of the experimental period. Quantification and statistical analysis revealed a significantly higher number of BrdU+ cells in the dentate gyrus of PDTC-treated DD mice, comparable to LD saline controls, than in the DD saline group $(p<0.05)$ (Fig. $5 B, C)$.

Constant darkness modulates protein levels of per 2 and npas 2 in the hippocampus in an NF- $\kappa \mathrm{B}$-dependent manner

Protein levels of per1, per2, per3, and npas2 were evaluated in hippocampal tissue of DD and LD mice (PDTC, ASA, and saline) by immunoblotting. As shown Figure 5, $D$ and $E$, per2 levels were significantly lower (significant main effect of light condition: $\left.F_{(1,23)}=8.29, p<0.01\right)$ and npas2 levels significantly higher in DD than in LD mice (significant main effect of light condition: $\left.F_{(1,23)}=7.75, p<0.05\right)$. Moreover, a significant main effect of drug $\left(F_{(2,23)}=4.64, p<0.05\right)$ and a significant interaction (light $\times$ drug $)\left(F_{(2,23)}=3.65, p<0.05\right)$ for per2 and for npas2 [significant main effect of drug: $F_{(2,23)}=4.82, p<0.05$; significant interaction (light $\times$ drug): $F_{(2,23)}=7.73, p<0.01$ ] were found. Post hoc comparisons showed statistically significant differences between DD saline controls and PDTC- and ASA- 
treated mice $(p<0.05)$. No significant effects of either light condition or drug treatment on perl or per3 protein levels were observed (data not shown).

NF- $\kappa \mathrm{B}$ activity is increased in hippocampal tissue of mice exposed to constant darkness

Nuclear protein extracts of hippocampal tissue of DD and LD mice $(n=7$ per group) were used for detecting and quantifying transcription factor activity of NF- $\kappa \mathrm{B}$ p 65 and p50 subunits using a highly specific and sensitive ELISA-based method. Statistical analysis of photometric measurements revealed a significant $(p<0.001$ for $\mathrm{p} 65$ and $\mathrm{p} 50)$ induction of NF- $\kappa$ B DNA binding activity in hippocampal nuclear extracts of DD compared to LD mice (Fig. $6 A, B$ ).

\section{Blockage of IL-6 prevents the effects of constant darkness on depression-like behavior}

A causal involvement of IL-6 in the behavioral depressogenic effect of DD was investigated by testing IL-6 knock-out (IL-6 $\mathrm{KO})$ mice and corresponding wild-type (WT) controls ( $n=8$ per group) in the FST and the TST after exposure to DD. In both tests, the percentage of time spent immobile was significantly lower in IL-6 KO mice than in WT mice $(p<0.05$ in both tests) (Fig. 6C,D).

\section{Discussion}

\section{Constant darkness is a chronobiological} model for depression in mice

Long-term light deprivation in the constant darkness paradigm has been shown to result in damage of monoaminergic neurons and to induce depression-like behavior in rats (Gonzalez and Aston-Jones, 2008). Interestingly, while extensive neuronal damage, including impaired dendritic arborization, neuronal death, and size reduction, has been reported so far mainly in the hippocampus in samples of depressed patients (Sapolsky, 2001; Sheline et al., 2003; McKinnon et al., 2009), there is also evidence for neuronal cell death in brain regions harboring monoaminergic neurotransmitter systems (Kitayama et al., 1994, 1997, 2008). We here show for the first time that in mice, long-term exposure to DD leads to the development of depression-like behavior, as demonstrated in the FST, the TST, and the SPT. Reduced cell proliferation in the hippocampal dentate gyrus as a result of DD further supports the role of $\mathrm{DD}$ as an animal model of depression since several lines of evidence indicate a role for adult hippocampal neurogenesis in the action of pharmacological and nonpharmacological interventions for depression in rodents (Sahay and Hen, 2007). Moreover, chronic stress, known as a precipitating factor for the development depression, decreases hippocampal neurogenesis (Dranovsky and Hen, 2006). Reduced hippocampal cell proliferation in DD therefore establishes an important parallel between this, chronobiological, and other existing animal models of depression. $0.01,{ }^{* *} p<0.001$.
A

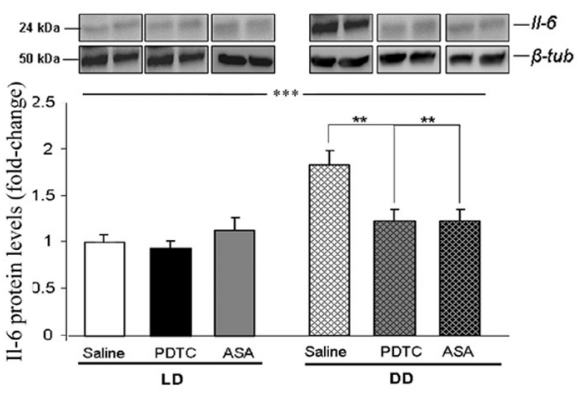

B

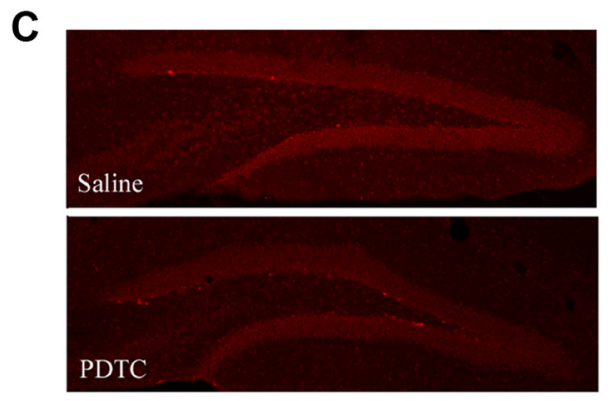

E

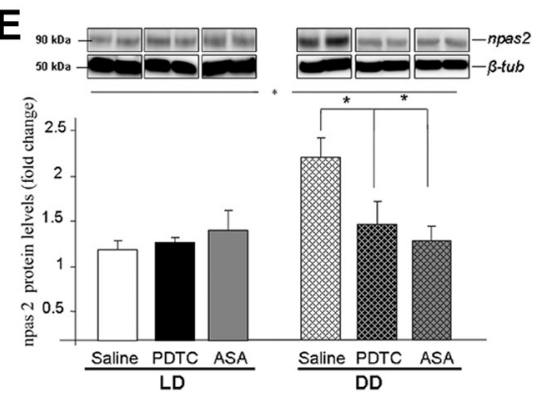

Figure 5. A, Hippocampal protein levels of IL-6 in LD and DD mice treated with PDTC, ASA, or saline controls. $\boldsymbol{B}$, Quantitative evaluation of BrdU + cells in the hippocampal subgranular zone in PDTC-treated and saline control DD mice. C, Representative zone in PDTC-treated and saline control DD mice. $\boldsymbol{D}, \boldsymbol{E}$, per2 (D) and npas2 (E) hippocampal protein levels of IL-6 in LD and DD mice With PDTC, ASA, or saline controls. Protein levels are ratios of optical densities. Values from the DD group are normalized to hoc comparisons performed subsequent to ANOVA analysis for evaluation of pairwise differences (see Results). ${ }^{*} p<0.05$, ${ }^{* *} p<$

Constant darkness modulates circulating and hippocampal cytokine and cytokine receptor levels and leads to Erk1/2 activation in the hippocampus

The "immune theory of depression" is based upon a large series of reports of elevated immune parameters in depressed patients and in several animal models (Zorrilla et al., 2001; Anisman et al., 2005; Raison et al., 2006; Miller et al., 2009). However, the precise cause of the inflammatory state in somatically healthy patients remains unclear. Here we demonstrate for the first time that long-term light deprivation leads to an elevation of circulating IL-6, one of the prominent cytokines associated with depression in both human patients and experimental animals (Maes et al., 1993, 1995; Sluzewska et al., 1996; Butterweck et al., 2003; Chourbaji et al., 2006; Wu and Lin, 2008). DD does not affect other mediators of the innate immune response, such as Il-1 $\beta$ and TNF- $\alpha$. Although alterations of both Il- $1 \beta$ and TNF- $\alpha$ have been reported in depressed patients (Licinio and Wong, 1999), it has been proposed that IL- 6 is one of the most reliable peripheral biomarkers in depression (Zorrilla et al., 2001; Mössner et al., 2007). Moreover, we also find that DD leads to increased protein 

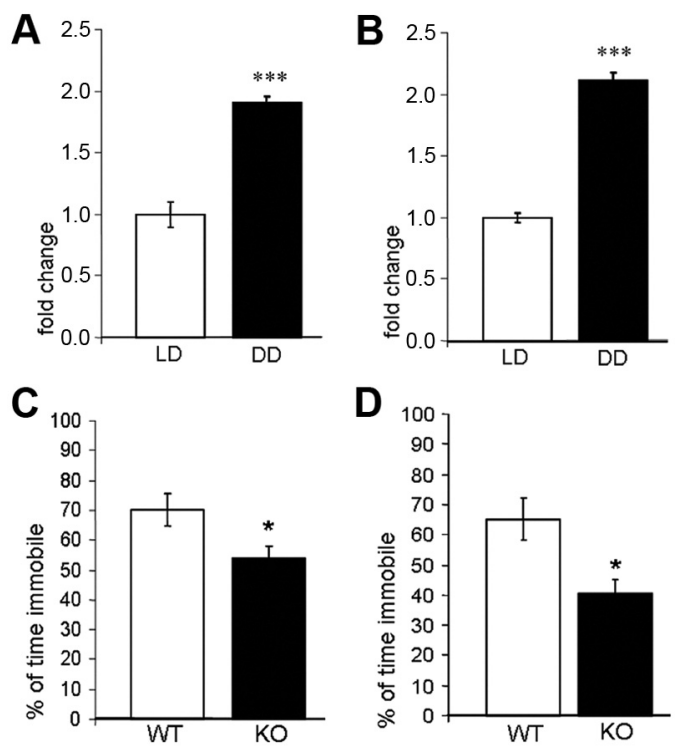

Figure 6. $\quad \boldsymbol{A}, \boldsymbol{B}$, Transcription factor $\mathrm{p} 65(\boldsymbol{A})$ and $\mathrm{p} 50(\boldsymbol{B})$ DNA binding activity in hippocampal nuclear extracts of $L D$ and DD mice. Photometric absorbance measurements of the DD group are normalized to those of the LD controls and depicted as fold changes. $C, D$, Immobility (percentage of total time) in the forced-swim test ( $\boldsymbol{C}$ ) and the tail-suspension test (D) in DD IL-6 K0 and WT mice. All data are displayed as mean \pm SEM. ${ }^{*} p<0.05,{ }^{* * *} p<0.001$.

levels of IL-6 and IL-1-R1 in the hippocampus, a limbic structure extensively studied in individuals with depression (MacQueen et al., 2003; Mayberg, 2003; Videbech and Ravnkilde, 2004; Sahay and Hen, 2007). IL-6 secretion in the brain occurs almost exclusively under pathological circumstances (Muñoz-Fernández and Fresno, 1998), and it has been shown that long-term exposure to this proinflammatory cytokine interferes with hippocampal neurogenesis in mice (Vallières et al., 2002). In rats, it has been described that intrahippocampal IL-6 treatment leads to an increase in depression-like behavior in the FST, which is paralleled by enhanced phosphorylation of Erk1/2 without affecting total levels of Erk1/2 (Wu and Lin, 2008). Similarly, we suggest that DDinduced enhancement of IL- 6 may lead activation of Erk $1 / 2$ since we observed an increase in the pErk1/2 in hippocampal tissue of mice of the DD group while levels of tErk1/2 remain unchanged.

Enhanced protein levels of IL1-R1 in DD mice is in support of recent reports suggesting blockage of IL1-R1 as a therapeutic strategy for the treatment of depression (Koo and Duman, 2009). Additionally, IL1-R1 is highly expressed in the granule cell layer of the hippocampal dentate gyrus (Parnet et al., 2002), suggesting the hippocampus as a target brain structure mediating the behavioral manifestations of IL1-R1 activation, such as depression-like symptoms and accompanying activation of inflammatory pathways (Miller et al., 2009).

Blockage of NF- $\kappa$ B ameliorates constant darkness-induced depression-like behavior, dampens the effect on hippocampal and systemic IL-6 levels, and prevents inhibition of hippocampal cell proliferation

We next examined the signal transduction pathways that could provide the molecular link between the exposure to DD, depression-like behavior, and elevated levels of IL-6. Disrupted sleep-wake cycles and sleep deprivation lead to activation of NF- $\kappa$ B (Motivala et al., 2005; Irwin et al., 2008), a transcription factor with a key role in triggering and coordinating innate and adaptative immune responses through the control of the expres- sion of a series of inflammatory genes, including IL-6 (Ghosh and Karin, 2002). Psychosocial stress, which is known to activate the immune response, both peripherally and in the brain (Miller et al., 2009), has been found to increase NF- $\kappa$ B activity in healthy individuals and to lead to an exacerbated stress response in patients suffering from depression (Bierhaus et al., 2003; Pace et al., 2006). We therefore decided to examine whether NF- $\kappa$ B was also involved in mediating the effects of DD, by pharmacologically blocking NF- $\kappa$ B activity using PDTC, ASA, and BAY 11-7082, a selective inhibitor of I $\kappa \mathrm{B} \alpha$ phosphorylation that most efficiently and selectively blocks NF- $\kappa$ B activity (Pierce et al., 1997). Application of PDTC not only leads to the restoration of control levels of immobility in the FST and the TST but also prevents the inhibitory activity of DD on hippocampal cell proliferation, supporting a causal involvement of NF- $\kappa \mathrm{B}$ signaling in both the depressogenic behavioral effects and the concomitant impairment of hippocampal cell proliferation induced by long-term light deprivation. These results are in line with a recent report describing the NF- $\kappa \mathrm{B}$ pathway as a critical mediator of depressive behavior and its requirement for the antineurogenic and anhedonic effects of repeated stress (Koo et al., 2010).

\section{Blockage of NF- $\kappa$ B blunts the effect of constant darkness on hippocampal protein levels of per 2 and npas 2}

Next we decided to evaluate whether the behavioral phenotype of $\mathrm{DD}$ and its associated inflammatory profile were paralleled by alterations in clock gene expression in the hippocampus. In a first survey, we decided to focus on those clock genes that have been implicated in depression previously (Partonen et al., 2007; Lavebratt et al., 2010; Soria et al., 2010). We found significantly reduced protein levels of per2 in hippocampal tissue of DD mice, and this effect was reversed by treatment with PDTC. Interestingly, DD did not affect protein levels of the other period proteins, per1 and per3, suggesting a selective effect on per2, which seems important for controlling neural stem/progenitor cell proliferation, cell death, and neurogenesis in the mouse dentate gyrus (Borgs et al., 2009) and has been associated with depression (Partonen et al., 2007; Lavebratt et al., 2010). Conversely to the reduced levels of per2, we found increased levels of npas2, an analog of clock that forms part of the positive arm of the molecular circadian feedback loop and is exclusively found in neurons (Reick et al., 2001), in hippocampal tissue of DD mice. Altered npas2 levels were returned to those of LD controls by treatment with both PDTC and ASA. npas2 has also been related to winter depression in humans (Partonen et al., 2007), and npas2deficient mice have been found to present with disrupted sleep patterns, disturbed behavioral adaptability, and abnormal emotional behaviors, supporting an involvement of npas 2 in mood regulation.

\section{Constant darkness activates NF- $\kappa \mathrm{B}$, and its effect on depression-like behavior depends on IL-6}

Enhanced DNA binding activity of NF- $\kappa \mathrm{B}$ in hippocampal tissue of DD mice additionally consolidates the proposed involvement of this canonical inflammatory pathway in the signal transduction processes mediating the depressogenic effects of constant darkness. Enhanced NF- $\kappa$ B activity following an acute stress procedure has been described in mouse hippocampal tissue (Koo et al., 2010) and peripherally in healthy human subjects and depressed patients (Bierhaus et al., 2003; Pace et al., 2006). Here we describe - to the best of our knowledge-for the first time increased NF- $\kappa$ B brain activity in an animal model of depression. Moreover, we further delineate the downstream molecular cas- 
cade by providing evidence that the behavioral effects of NF- $\kappa \mathrm{B}$ are mediated through IL-6, since IL-6 KO mice are resistant to induction of depression-like behavior by light deprivation in the constant darkness paradigm.

To conclude, we report that light deprivation in the constant darkness paradigm serves as chronobiological model of depression in mice, in which the behavioral phenotype is reflected by alterations in hippocampal cell proliferation, augmented circulating and local hippocampal IL-6 levels, and disruption of elements of the molecular circadian machinery. We further propose that the development of the behavioral phenotype and its associated biochemical and molecular correlates involve the NF- $\kappa \mathrm{B}$ signaling pathway and that they are likely to be mediated through IL-6 as downstream effector molecule. This study identifies for the first time some of the molecular players providing a functional link between the inflammatory and the circadian system in the constant darkness mouse model of depression.

\section{References}

Anisman H, Merali Z, Poulter MO, Hayley S (2005) Cytokines as a precipitant of depressive illness: animal and human studies. Curr Pharm Des 11:963-972.

Baldwin DS, Papakostas GI (2006) Symptoms of fatigue and sleepiness in major depressive disorder. J Clin Psychiatry 67 [Suppl 6]:9-15.

Bierhaus A, Wolf J, Andrassy M, Rohleder N, Humpert PM, Petrov D, Ferstl R, von Eynatten M, Wendt T, Rudofsky G, Joswig M, Morcos M, Schwaninger M, McEwen B, Kirschbaum C, Nawroth PP (2003) A mechanism converting psychosocial stress into mononuclear cell activation. Proc Natl Acad Sci U S A 100:1920-1925.

Boivin DB (2000) Influence of sleep-wake and circadian rhythm disturbances in psychiatric disorders. J Psychiatry Neurosci 25:446-458.

Borgs L, Beukelaers P, Vandenbosch R, Nguyen L, Moonen G, Maquet P, Albrecht U, Belachew S, Malgrange B (2009) Period 2 regulates neural stem/progenitor cell proliferation in the adult hippocampus. BMC Neurosci 10:30

Brunello N, Alboni S, Capone G, Benatti C, Blom JM, Tascedda F, Kriwin P, Mendlewicz J (2006) Acetylsalicylic acid accelerates the antidepressant effect of fluoxetine in the chronic escape deficit model of depression. Int Clin Psychopharmacol 21:219-225.

Butterweck V, Prinz S, Schwaninger M (2003) The role of interleukin-6 in stress-induced hyperthermia and emotional behaviour in mice. Behav Brain Res 144:49-56.

Castagné V, Porsolt RD, Moser P (2009) Use of latency to immobility improves detection of antidepressant-like activity in the behavioral despair test in the mouse. Eur J Pharmacol 616:128-133.

Chourbaji S, Urani A, Inta I, Sanchis-Segura C, Brandwein C, Zink M, Schwaninger M, Gass P (2006) IL-6 knockout mice exhibit resistance to stress-induced development of depression-like behaviors. Neurobiol Dis 23:587-594.

Cryan JF, Page ME, Lucki I (2002) Noradrenergic lesions differentially alter the antidepressant-like effects of reboxetine in a modified forced swim test. Eur J Pharmacol 436:197-205.

Dantzer R, O'Connor JC, Freund GG, Johnson RW, Kelley KW (2008) From inflammation to sickness and depression: when the immune system subjugates the brain. Nat Rev Neurosci 9:46-56.

Dranovsky A, Hen R (2006) Hippocampal neurogenesis: regulation by stress and antidepressants. Biol Psychiatry 59:1136-1143.

Fava M (2004) Daytime sleepiness and insomnia as correlates of depression. J Clin Psychiatry 65 [Suppl 16]:27-32.

Ghosh S, Karin M (2002) Missing pieces in the NF-kappaB puzzle. Cell 109 [Suppl]:S81-S96.

González MM, Aston-Jones G (2006) Circadian regulation of arousal: role of the noradrenergic locus coeruleus system and light exposure. Sleep 29:1327-1336.

Gonzalez MM, Aston-Jones G (2008) Light deprivation damages monoamine neurons and produces a depressive behavioral phenotype in rats. Proc Natl Acad Sci U S A 105:4898-4903.

Ibarguen-Vargas Y, Surget A, Vourc'h P, Leman S, Andres CR, Gardier AM, Belzung C (2009) Deficit in BDNF does not increase vulnerability to stress but dampens antidepressant-like effects in the unpredictable chronic mild stress. Behav Brain Res 202:245-251.

Irwin MR, Wang M, Ribeiro D, Cho HJ, Olmstead R, Breen EC, MartinezMaza O, Cole S (2008) Sleep loss activates cellular inflammatory signaling. Biol Psychiatry 64:538-540.

Kitayama I, Nakamura S, Yaga T, Murase S, Nomura J, Kayahara T, Nakano K (1994) Degeneration of locus coeruleus axons in stress-induced depression model. Brain Res Bull 35:573-580.

Kitayama I, Yaga T, Kayahara T, Nakano K, Murase S, Otani M, Nomura J (1997) Long-term stress degenerates, but imipramine regenerates, noradrenergic axons in the rat cerebral cortex. Biol Psychiatry 42:687-696.

Kitayama IT, Otani M, Murase S (2008) Degeneration of the locus ceruleus noradrenergic neurons in the stress-induced depression of rats. Ann N Y Acad Sci 1148:95-98.

Koo JW, Duman RS (2009) Evidence for IL-1 receptor blockade as a therapeutic strategy for the treatment of depression. Curr Opin Investig Drugs 10:664-671.

Koo JW, Russo SJ, Ferguson D, Nestler EJ, Duman RS (2010) Nuclear factorkappaB is a critical mediator of stress-impaired neurogenesis and depressive behavior. Proc Natl Acad Sci U S A 107:2669-2674.

Lam RW (2006) Sleep disturbances and depression: a challenge for antidepressants. Int Clin Psychopharmacol 21 [Suppl 1]:S25-S29.

Lavebratt C, Sjoholm LK, Partonen T, Schalling M, Forsell Y (2010) PER2 variantion is associated with depression vulnerability. Am J Med Genet B Neuropsychiatr Genet 153B:570-581.

Licinio J, Wong ML (1999) The role of inflammatory mediators in the biology of major depression: central nervous system cytokines modulate the biological substrate of depressive symptoms, regulate stress-responsive systems, and contribute to neurotoxicity and neuroprotection. Mol Psychiatry 4:317-327.

MacQueen GM, Campbell S, McEwen BS, Macdonald K, Amano S, Joffe RT, Nahmias C, Young LT (2003) Course of illness, hippocampal function, and hippocampal volume in major depression. Proc Natl Acad Sci U S A 100:1387-1392.

Maes M, Scharpé S, Meltzer HY, Bosmans E, Suy E, Calabrese J, Cosyns P (1993) Relationships between interleukin-6 activity, acute phase proteins, and function of the hypothalamic-pituitary-adrenal axis in severe depression. Psychiatry Res 49:11-27.

Maes M, Meltzer HY, Bosmans E, Bergmans R, Vandoolaeghe E, Ranjan R, Desnyder R (1995) Increased plasma concentrations of interleukin-6, soluble interleukin-6, soluble interleukin-2 and transferrin receptor in major depression. J Affect Disord 34:301-309.

Mayberg HS (2003) Positron emission tomography imaging in depression: a neural systems perspective. Neuroimaging Clin N Am 13:805-815.

McKinnon MC, Yucel K, Nazarov A, MacQueen GM (2009) A metaanalysis examining clinical predictors of hippocampal volume in patients with major depressive disorder. J Psychiatry Neurosci 34:41-54.

Miller AH, Maletic V, Raison CL (2009) Inflammation and its discontents: the role of cytokines in the pathophysiology of major depression. Biol Psychiatry 65:732-741.

Mössner R, Mikova O, Koutsilieri E, Saoud M, Ehlis AC, Müller N, Fallgatter AJ, Riederer P (2007) Consensus paper of the WFSBP Task Force on Biological Markers: biological markers in depression. World J Biol Psychiatry 8:141-174.

Motivala SJ, Sarfatti A, Olmos L, Irwin MR (2005) Inflammatory markers and sleep disturbance in major depression. Psychosom Med 67:187-194.

Muñoz-Fernández MA, Fresno M (1998) The role of tumour necrosis factor, interleukin 6, interferon-gamma and inducible nitric oxide synthase in the development and pathology of the nervous system. Prog Neurobiol 56:307-340.

Pace TW, Mletzko TC, Alagbe O, Musselman DL, Nemeroff CB, Miller AH, Heim CM (2006) Increased stress-induced inflammatory responses in male patients with major depression and increased early life stress. Am J Psychiatry 163:1630-1633.

Parnet P, Kelley KW, Bluthé RM, Dantzer R (2002) Expression and regulation of interleukin-1 receptors in the brain. Role in cytokines-induced sickness behavior. J Neuroimmunol 125:5-14.

Partonen T, Treutlein J, Alpman A, Frank J, Johansson C, Depner M, Aron L, Rietschel M, Wellek S, Soronen P, Paunio T, Koch A, Chen P, Lathrop M, Adolfsson R, Persson ML, Kasper S, Schalling M, Peltonen L, Schumann G (2007) Three circadian clock genes Per2, Arntl, and Npas2 contribute to winter depression. Ann Med 39:229-238. 
Pierce JW, Schoenleber R, Jesmok G, Best J, Moore SA, Collins T, Gerritsen ME (1997) Novel inhibitors of cytokine-induced IkappaBalpha phosphorylation and endothelial cell adhesion molecule expression show antiinflammatory effects in vivo. J Biol Chem 272:21096-21103.

Pollak DD, Scharl T, Leisch F, Herkner K, Villar SR, Hoeger H, Lubec G (2005) Strain-dependent regulation of plasticity-related proteins in the mouse hippocampus. Behav Brain Res 165:240-246.

Pollak DD, Monje FJ, Zuckerman L, Denny CA, Drew MR, Kandel ER (2008) An animal model of a behavioral intervention for depression. Neuron 60:149-161.

Porsolt RD, Bertin A, Jalfre M (1977) Behavioral despair in mice: a primary screening test for antidepressants. Arch Int Pharmacodyn Ther 229:327-336.

Raison CL, Capuron L, Miller AH (2006) Cytokines sing the blues: inflammation and the pathogenesis of depression. Trends Immunol 27:24-31.

Reick M, Garcia JA, Dudley C, McKnight SL (2001) NPAS2: an analog of clock operative in the mammalian forebrain. Science 293:506-509.

Rivas MA, Carnevale RP, Proietti CJ, Rosemblit C, Beguelin W, Salatino M, Charreau EH, Frahm I, Sapia S, Brouckaert P, Elizalde PV, Schillaci R (2008) TNF alpha acting on TNFR1 promotes breast cancer growth via p42/P44 MAPK, JNK, Akt and NF-kappa B-dependent pathways. Exp Cell Res 314:509-529.

Rosen LN, Targum SD, Terman M, Bryant MJ, Hoffman H, Kasper SF, Hamovit JR, Docherty JP, Welch B, Rosenthal NE (1990) Prevalence of seasonal affective disorder at four latitudes. Psychiatry Res 31:131-144.

Sahay A, Hen R (2007) Adult hippocampal neurogenesis in depression. Nat Neurosci 10:1110-1115.

Sapolsky RM (2001) Depression, antidepressants, and the shrinking hippocampus. Proc Natl Acad Sci U S A 98:12320-12322.

Sheline YI, Gado MH, Kraemer HC (2003) Untreated depression and hippocampal volume loss. Am J Psychiatry 160:1516-1518.

Sluzewska A, Rybakowski J, Bosmans E, Sobieska M, Berghmans R, Maes M, Wiktorowicz K (1996) Indicators of immune activation in major depression. Psychiatry Res 64:161-167.

Soria V, Martínez-Amorós E, Escaramís G, Valero J, Pérez-Egea R, García C, Gutiérrez-Zotes A, Puigdemont D, Bayés M, Crespo JM, Martorell L, Vilella E, Labad A, Vallejo J, Pérez V, Menchón JM, Estivill X, Gratacòs M, Urretavizcaya M (2010) Differential association of circadian genes with mood disorders: CRY1 and NPAS2 are associated with unipolar major depression and CLOCK and VIP with bipolar disorder. Neuropsychopharmacology 35:1279-1289.

Souêtre E, Salvati E, Belugou JL, Pringuey D, Candito M, Krebs B, Ardisson JL, Darcourt G (1989) Circadian rhythms in depression and recovery: evidence for blunted amplitude as the main chronobiological abnormality. Psychiatry Res 28:263-278.

Srinivasan V, Smits M, Spence W, Lowe AD, Kayumov L, Pandi-Perumal SR, Parry B, Cardinali DP (2006) Melatonin in mood disorders. World J Biol Psychiatry 7:138-151.

Steiner MA, Marsicano G, Nestler EJ, Holsboer F, Lutz B, Wotjak CT (2008) Antidepressant-like behavioral effects of impaired cannabinoid receptor type 1 signaling coincide with exaggerated corticosterone secretion in mice. Psychoneuroendocrinology 33:54-67.

Vallières L, Campbell IL, Gage FH, Sawchenko PE (2002) Reduced hippocampal neurogenesis in adult transgenic mice with chronic astrocytic production of interleukin-6. J Neurosci 22:486-492.

Vgontzas AN, Zoumakis M, Papanicolaou DA, Bixler EO, Prolo P, Lin HM, Vela-Bueno A, Kales A, Chrousos GP (2002) Chronic insomnia is associated with a shift of interleukin-6 and tumor necrosis factor secretion from nighttime to daytime. Metabolism 51:887-892.

Vgontzas AN, Zoumakis M, Bixler EO, Lin HM, Prolo P, Vela-Bueno A, Kales A, Chrousos GP (2003) Impaired nighttime sleep in healthy old versus young adults is associated with elevated plasma interleukin- 6 and cortisol levels: physiologic and therapeutic implications. J Clin Endocrinol Metab 88:2087-2095.

Videbech P, Ravnkilde B (2004) Hippocampal volume and depression: a meta-analysis of MRI studies. Am J Psychiatry 161:1957-1966.

Wirz-Justice A (2006) Biological rhythm disturbances in mood disorders. Int Clin Psychopharmacol 21 [Suppl 1]:S11-S15.

Wu TH, Lin CH (2008) IL-6 mediated alterations on immobile behavior of rats in the forced swim test via ERK1/2 activation in specific brain regions. Behav Brain Res 193:183-191.

Zhang X, Luhrs KJ, Ryff KA, Malik WT, Driscoll MJ, Culver B (2009) Suppression of nuclear factor kappa B ameliorates astrogliosis but not amyloid burden in APPswe/PS1dE9 mice. Neuroscience 161:53-58.

Zorrilla EP, Luborsky L, McKay JR, Rosenthal R, Houldin A, Tax A, McCorkle R, Seligman DA, Schmidt K (2001) The relationship of depression and stressors to immunological assays: a meta-analytic review. Brain Behav Immun 15:199-226. 